The impact of body image-related cognitive fusion on eating psychopathology

Inês A. Trindade, M.S. ${ }^{1}$ *

Cláudia Ferreira, M.S., Ph.D ${ }^{1}$

${ }^{1}$ University of Coimbra, Portugal

CINEICC - Cognitive-Behavioral Research Center

* Correspondence concerning this article should be addressed to:

Inês A. Trindade

CINEICC, Faculdade de Psicologia e Ciências da Educação,

Universidade de Coimbra

Rua do Colégio Novo, Apartado 6153

3001-802 Coimbra, Portugal

Email: ines.almeidatrindade@gmail.com

Telephone: (+351) 239851450

Fax: (+351) 239851462 


\title{
The impact of body image-related cognitive fusion on eating psychopathology
}

\begin{abstract}
Recent research has shown that cognitive fusion underlies psychological inflexibility and in consequence various forms of psychopathology. However, the role of cognitive fusion specifically related to body image on eating psychopathology remained to be examined.

The current study explores the impact of cognitive fusion concerning body image in the relation between acknowledged related risk factors and eating psychopathology in a sample of 342 female students.

The impact of body dissatisfaction and social comparison through physical appearance on eating psychopathology was partially mediated by body image-related cognitive fusion. The results highlight the importance of cognitive defusion in the treatment of eating disorders.
\end{abstract}

Keywords: Body image-related cognitive fusion; eating psychopathology; body dissatisfaction; social comparison; mediation analysis. 


\section{Introduction}

Acceptance and Commitment Therapy (ACT) aims to enhance psychological flexibility, which refers to "the process of contacting the present moment fully as a conscious human being and persisting or changing behavior in the service of chosen values" (Hayes, Luoma, Bond, Masuda, \& Lillis, 2006, p.9). One key process that threatens psychological flexibility is cognitive fusion (Hayes, 2004; Hayes, Strosahl, \& Wilson, 1999).

Cognitive fusion can be described as the degree to which an individual interacts with events considering only their verbal functions rather than their direct ones (Hayes et al., 1999). This process results in self-identification with one's thoughts and in inability in to consider them as part of inner experience (rather than statements of facts) and consequently taking objective attitudes towards them (Eifert et al., 2009). Therefore, ACT's overall therapeutic goal is to promote cognitive defusion and acceptance of inner events. These strategies are intended to construct a healthy skepticism about one's thoughts, enabling a better contact with the present moment (Hayes, 1989) and the individual's values (Fletcher \& Hayes, 2005).

Eating disorders have been considered an illness of psychological inflexibility, i.e. the incapacity of behaving flexibly while dealing with negative sensations, thoughts and feelings (e.g., Merwin et al. 2011). Although scarce, literature has been highlighting cognitive fusion in eating psychopathology (e.g. Hayes \& Pankey, 2002; Ferreira, Trindade, Duarte, \& Pinto-Gouveia, 2013). Also, research has suggested that ACT is effective and may even achieve better results than regular behavioral interventions in these disorders (e.g., Butryn et al., 2013; Juarascio, Forman, \& Herbert, 2010; Sandoz, Wilson, \& DuFrene, 2011). 
Body dissatisfaction (e.g., Stice, Marti, \& Durant, 2011) and unfavorable social comparisons (e.g., Troop, Allen, Treasure, \& Katzman, 2003) represent nuclear risk factors for eating psychopathology. Nevertheless, although almost all women compare themselves physically with other women, which at some point triggers feelings of body dissatisfaction and ranking disadvantage, not all develop eating psychopathology. This seems to imply that other processes may also be involved in these conditions. We hypothesized that women who get fused and tangled with thoughts relating to body image have greater tendencies of developing disordered mechanisms in order to "correct" their body dissatisfaction and social disadvantage. Therefore, this study tests whether body image-related cognitive fusion mediates the relationship between main risk factors and eating psychopathology.

\section{Materials and methods}

\subsection{Participants}

Participants included 342 female college students (13 to 25 years old) with a mean age of 17.76 years $(S D=2.63)$ and $11.40(S D=2.46)$ of years of education. Their BMI mean was $21.14(S D=2.80)$, corresponding to normal weight values (WHO, 1995).

\subsection{Procedures}

The research protocol was approved by the Ethics Committees of the educational institutions enrolled in the study. Participants and their parents (if the subjects were minor) gave their written informed consent after being assured of the confidentiality and voluntary character of their collaboration and informed about the aims of the study. 


\subsection{Data analysis}

Descriptive statistics were used to explore the sample characteristics in study's variables and product-moment Pearson correlation analyses were performed (Cohen, Cohen, West, \& Aiken, 2003). Two mediation analyses were conducted according to Baron and Kenny (1986), in which body image-related cognitive fusion was tested as mediator on the association of body image dissatisfaction (Model 1) and social comparison based on physical appearance with peers (Model 2; predictor variables) towards eating psychopathology (dependent variable).

\subsection{Measures}

Figure Rating Scale (FRS; Thompson \& Altabe, 1991; Ferreira, 2003). The FRS evaluates body dissatisfaction through a series of nine silhouettes of different dimensions. Body dissatisfaction (BD) was calculated through the discrepancy between the silhouettes chosen by the participant as her actual and desired ones. The questionnaire has good temporal reliability, as well as good convergent and divergent validities (Thompson \& Altabe, 1991).

Social Comparison Rating Scale (SCRS; Allan \& Gilbert, 1995; Gato, 2003). It is an 11-item scale which evaluates one's self-perception of social rank in a semantic differential methodology. The SCRS presents good psychometric properties and negative correlations with psychopathology.

Social Comparison through Physical Appearance Scale (SCPAS; Ferreira, PintoGouveia, \& Duarte, 2013). The SCPAS assesses the subjective perception based on physical appearance of women's social standing and group fit. The participants are asked to compare themselves with peers (Part A) and with models or other celebrities (Part B). The 
scale revealed high internal consistency in the original study, on both Part A $(\alpha=.94)$ and Part B $(\alpha=.96)$.

Cognitive Fusion Questionaire-28 (CFQ-28; Gillanders et al., 2010; PintoGouveia, Dinis, Gregório, \& Pinto, 2011). It consists of 28 items, each of them taking the form of a statement alluding to literality and entanglement with thoughts in order to measure broad cognitive fusion and defusion. The CFQ-28's internal consistency values were good both in the original study and in the Portuguese validation.

Cognitive Fusion Questionnaire - Body Image (CFQ-BI; Ferreira, Trindade, et al., 2013). The CFQ-BI is a 15-item self-report scale based on the CFQ-28's items so as to evaluate body image-related cognitive fusion. The CFQ-BI showed good internal consistency $(\alpha=.97)$, and good temporal, discriminant, convergent and divergent validities in the original study.

Mindful Attention Awareness Scale (MAAS; Brown \& Ryan, 2003; Gregório \& Pinto-Gouveia, in press). It is a 15-item instrument which evaluates mindfulness dispositional characteristics. The MAAS was shown to hold strong psychometric qualities ( $\alpha=.84$ in the original study and .90 in the Portuguese validation).

Eating Disorder Examination Questionnaire (EDE-Q; Fairburn \& Beglin, 1994; Machado, 2007). The EDE-Q is a self-report measure that assesses attitudes and behavioral traits of eating disorders. It has demonstrated good reliability and the capacity to differentiate cases from non-cases of eating disorders (see also Fairburn, 2008).

The Cronbach's alphas for all of the study variables are reported in Table 1.

\section{Results}

\subsection{Preliminary analyses}


Analysis of Skewness and Kurtosis'values and visual inspection of the distributions confirmed the assumption of normality. Preliminary data analyses indicated that this data was suitable for regression analyses following the assumptions of normality, linearity, homoscedasticity, independence of errors and multicolinearity (Kline, 1998).

\subsection{Descriptive analyses}

Descriptive statistics regarding the studied variables for the total sample are presented in Table 1.

\subsection{Correlations}

Results demonstrated that the measures of cognitive fusion, CFQ-BI and CFQ_F, held positive and strong correlations between each other and with higher levels of EDE-Q. Moreover, those measures held positive correlations with BD (weak in case of the CFQ_F and moderated in case of the CFQ-BI). Also, these scales showed negative correlations with MAAS, SCRS and SCPAS. In particular, CFQ-BI correlated positively with BMI (see table 1).

[insert Table 1 about here]

\subsection{Mediation analyses}

\subsubsection{Body image-related cognitive fusion as a mediator between body dissatisfaction} and eating psychopathology

A regression analysis having $\mathrm{BD}$ as the independent variable and EDE-Q as the dependent variable showed significance $\left[F_{(1,328)}=173.65, p<.001\right]$, explaining $34.6 \%$ of EDE-Q $(\beta=.59, p<.001)$. The second model (BD as predictor of CFQ-BI) was also 
significant $\left[F_{(1,329)}=68.99, p<.001\right]$, accounting for $17.3 \%$ of the variance of CFQ-BI with a $\beta=.42(p<.001)$. The final model, having BD and CFB-BI as independent variables and EDE-Q as the dependent variable $\left[F_{(2,327)}=326.40, p<.001\right]$, explained $67 \%$ of the variance in eating psychopathology. Also, when the mediator is added, BD's $\beta$ is reduced to $.33(p<.001)$. The Sobel test $(z=13.13, p<.001)$ confirmed that CFQ-BI partially mediates the effect of BD on eating psychopathology severity (Model 1, Figure 1).

[insert Figure 1 about here]

\subsubsection{Body image-related cognitive fusion as a mediator between social comparison based on physical appearance and eating psychopathology}

To explore the meditational function of CFQ-BI on the relationship between SCPAS and EDE-Q the same procedure was conducted.

In the first step (SCPAS predicting EDE-Q), a significant model was obtained $\left[F_{(1,328)}\right.$ $=95.91, p<.001]$, accounting for $23 \%$ of EDE-Q $(\beta=-.48, p<.001)$. In the second step (SCPAS predicting CFQ-BI), the model was also significant $\left[R^{2}=.28, F_{(1,329)}=127.33, p\right.$ $<.001]$ with $\beta=-.53(p<.001)$. Finally, when SCPAS and CFQ-BI were used as independent variables, and EDE-Q as the dependent variable, the obtained model $\left[F_{(2,327)}=\right.$ $230.40, p<.001]$ explained $59 \%$ of the variance of EDE-Q. In this model the predictor's $\beta$ is reduced to $-.10(p=.017)$. The Sobel test $(z=-8.12, p<.001)$ indicated that CFQ-BI partially mediates the effect of SCPAS on EDE-Q (Model 2, Figure 1).

\section{Discussion and conclusions}


In this study, body image-related cognitive fusion was shown to be positively associated with broad cognitive fusion as expected (Ferreira, Trindade, et al., 2013), and with the incapacity of being conscious of the present moment. Indeed, the essence of this process leads one to lose contact with the present not just in social and physical terms but also psychologically (Hayes et al., 1999), as individuals fused with their cognitions fail to observe the content of their thoughts and act automatically to certain events (Hayes, 1989).

Additionally, cognitive fusion concerning body image was linked to unfavorable social rank perceptions not only when social ranking is based on physical appearance, but also in a general dimension. Specifically in relation to eating-related symptoms, this study revealed that cognitive fusion regarding body image is associated with greater body dissatisfaction and eating psychopathology severity. These results confirm our hypothesis and add to the existing research showing that the women get are more fused and tangled with thoughts about their body image, treating them as factual, tend to present more unfavorable social comparisons, experience higher body dissatisfaction and demonstrate higher tendencies to engage in disordered eating.

The mediation analyses indicated that body image-related cognitive fusion partially mediates the relationship of body dissatisfaction and social comparison through physical appearance towards the severity of eating psychopathology. These results suggest that the degree to which these factors have an impact on eating psychopathology partially depends upon on how one is fused with the thoughts about his or her body image. These results expand preceding research, highlighting how broad cognitive fusion is associated with disordered eating (e.g., Hayes \& Pankey, 2002). They also complement the research concerning the role of body image dissatisfaction and social comparison through physical appearance in eating disorders' vulnerability (e.g. Pinto-Gouveia, Ferreira, \& Duarte, 2012; 
Stice et al., 2011). In fact, these results show that neither body dissatisfaction nor unfavourable social comparison based on physical appearance necessarily underlie engagement in disordered eating, and that cognitive fusion plays an important role in this association.

These new findings cannot be considered without taking into account some limitations. The amount of variables included in the study was intentionally limited in order to obtain a preliminary comprehension of body image-related cognitive fusion's impact on eating psychopathology. Another limitation of the present study was the reliance on a crosssectional design which did not allow for casual inferences to be derived. In the future, longitudinal research should be performed with eating disorders treatment samples in order to confirm the directionality and predictability of the study variables.

Finally, we believe this study offers significant novel data for research and clinical work on eating disorders, presenting new empirical support to the interventions focused in the development of cognitive defusion. 


\section{References}

Allan, S., \& Gilbert, P. (1995). A social comparison scale: Psychometric properties and relationship to psychopathology. Personality and Individual Differences, 19 (3), 293-299. doi:10.1016/0191-8869(95)00086-L.

Baron, M., \& Kenny, D. (1986). The moderator-mediator variable distinction in social psychological research: Conceptual, strategic, and statistical considerations. Journal of Personality and Social Psychology, 51(6), 1173-1182. doi:10.1037/00223514.51.6.1173.

Brown. K. W., \& Ryan, R. M. (2003). The Benefits of Being Present: Mindfulness and Its Role in Psychological Well-Being. Journal of Personality and Social Psychology, 84, 822-848.

Butryn, M. L., Juarascio, A., Shaw, J., Kerrigan, S. G., Clark, V., O'Planick, A., Forman E. M. (2013). Mindfulness and its relationship with eating disorders symptomatology in women receiving residential treatment Mindfulness and its relationship with eating disorders symptomatology in women receiving residential treatment. Eating Behaviors, 14, 13-6.

Cohen, J., Cohen, P. West, S. \& Aiken, L. (2003). Applied multiple regression/correlation analysis for the behavioural sciences (3th ed.). New Jersey: Lawrence Erlbaum Associates.

Eifert, G. H., Forsyth, J. P., Arch, J., Espejo, E., Keller, M., \& Langer, D. (2009). Acceptance and commitment therapy for anxiety disorders: Three case studies exemplifying a unified treatment protocol. Cognitive Behavioral Practice, 16, 368385. 
Fairburn, C.G. (2008). Cognitive behavior therapy and eating disorders. New York: Guilford Press.

Fairburn, C. G., \& Beglin, S. J. (1994). Assessment of eating disorders: Interview or self-report questionnaire? International Journal of Eating Disorders, 16, 363370.

Ferreira, C. (2003). Anorexia Nervosa: A expressão visível do invisível. Contributos para a avaliação de atitudes e comportamentos em relação ao peso e à imagem corporal [Anorexia Nervosa: The visible expression of the invisible. Contributions for the assessment of attitudes and behaviors in relation to weight and body image]. (Unpublished master's thesis). University of Coimbra, Coimbra.

Ferreira, C., Pinto-Gouveia, J., \& Duarte, C. (2013). Physical appearance as a measure of social ranking: The role of a new scale to understand the relationship between weight and dieting. Clinical Psychology \& Psychotherapy, 20, 55-66. doi:10.1002/cpp.769.

Ferreira, C., Trindade, I. A., Duarte, C., \& Pinto-Gouveia, J. (2013). Getting entangled with body image: Development and validation of a new measure. Manuscript in preparation.

Fletcher, L., \& Hayes, S. C. (2005). Relational Frame Theory, Acceptance and Commitment Therapy, and a functional analytic definition of mindfulness. Journal of Rational-Emotive and Cognitive-Behavioral Therapy, 23(4), 315-336.

Gato, J. (2003). Evolução e ansiedade social [Evolution and social anxiety]. (Unpublished master's thesis). University of Coimbra, Coimbra.

Gillanders, D., Bolderston, H., Dempster, M., Bond, F., Campbell, L., Kerr, S., Tansey, L., Clarke, S., Remington, B., Flaxman, P., Deans, G., Bastien, J., Moore, D., \& 
Hermann, B. (2010, June). The Cognitive Fusion Questionnaire: Further developments in measuring cognitive fusion. Conference presented at the Association for Contextual Behavioral Science, World Congress VIII, Reno, NV.

Gregório, S., \& Pinto-Gouveia, J. (in press). Mindful attention and awareness: relationships with psychopathology and emotion regulation. Spanish Journal of Psychology, 16.

Hayes, S. C. (Ed.). (1989). Rule-governed behavior: Cognition, contingencies, and instructional control. New York: Plenum.

Hayes, S. C. (2004). Acceptance and commitment therapy, relational frame theory, and the third wave of behavior therapy. Behavior Therapy, 35, 639-665.

Hayes, S. C., \& Pankey, J. (2002). Experiencial Avoidance, Cognive Fusion and an ACT Approach to Anorexia Nervosa. Cognitive and Behavioral Science, 9, 243247.

Hayes, S. C., Luoma, J. B., Bond, F., Masuda, A., \& Lillis, J. (2006). Acceptance and Commitment Therapy: Model, processes and outcomes. Behaviour Research and Therapy, 44, 1-25.

Hayes, S. C., Strosahl, K. D., \& Wilson, K. G. (1999). Acceptance and Commitment Therapy: An experiential approach to behavior change. New York: Guilford Press.

Juarascio, A. S., Forman, E. M., \& Herbert, J. D. (2010). Acceptance and commitment therapy versus cognitive therapy for the treatment of comorbid eating pathology . Behavior Modification, 34(2), 175-190.

Kline, R. (1998). Principles and Practice of Structural Equation Modelling. New York: The Guilford Press.

Machado, P. P. P. (2007). Versão Portuguesa do EDE-Q, $5^{\text {a }}$ edição [Portuguese Version of the EDE-Q, 5th edition]. Unpublished manuscript. University of Minho. 
Merwin, R. M., Timko, C. A., Moskovich, A. A., Ingle, K. K., Bulik, C. M., \& Zucker, N. L. (2011). Psychological Inflexibility and Symptom Expression in Anorexia Nervosa. Eating Disorders, 19, 62-82.

Pinto-Gouveia, J., Dinis, A., Gregório S. \& Pinto, A. (2011). The Preliminary Psychometric Properties of the Portuguese Version of the Cognitive Fusion Questionnaire. Manuscript in preparation.

Pinto-Gouveia, J., Ferreira, C., \& Duarte, C. (2012). Thinness in the pursuit for social safeness: An integrative model of social rank mentality to explain eating psychopathology. Clinical Psychology and Psychotherapy. doi: 10.1002/cpp.1820

Sandoz, E., Wilson, K. G., \& DuFrene, T. (2011). Acceptance and Commitment Therapy for Eating Disorders: A Process-Focused Guide to Treating Anorexia and Bulimia. New Harbinger Publications.

Stice, E., Marti, C. N., \& Durant, S. (2011) Risk factors for onset of eating disorders: Evidence of multiple risk pathways from an 8-year prospective study. Behavior Research and Therapy, 10, 622-627. doi: 10.1016/j.brat.2011.06.009.

Thompson, J. K., \& Altabe, M. N. (1991). Psychometric qualities of the figure rating scale. International Journal of Eating Disorders, 10, 615-619. doi: 10.1002/1098$108 X(199109) 10: 5$.

Troop, N. A., Allan, S., Treasure, J. L. \& Katzman, M. (2003). Social comparison and submissive behaviour in eating disorders. Psychology and Psychotherapy: Theory, Research and Practice, 76, 237-249.

WHO (1995). Physical status: the use and interpretation of anthropometry. Reports of a WHO Expert Commitee. WHO Technical Report series 854. Geneva: World Health Organization. 


\section{Table 1}

Cronbach's alphas, Means (M), Standard Deviations (SD), and Intercorrelation scores on self-report measures $(N=342)$

\begin{tabular}{|c|c|c|c|c|c|c|c|c|c|c|c|}
\hline Measures & $\alpha$ & $M$ & $S D$ & 1 & 2 & 3 & 4 & 5 & 6 & 7 & 8 \\
\hline 1. BMI & - & 21.54 & 8.68 & 1 & & & & & & & \\
\hline 2. $\mathrm{BD}$ & - & .56 & .94 & $.57 * * *$ & 1 & & & & & & \\
\hline 3. SCRS & .89 & 65.23 & 13.72 & -.09 & $-.23^{* * *}$ & 1 & & & & & \\
\hline $\begin{array}{l}\text { 4. SCPAS } \\
\text { (peers) }\end{array}$ & .95 & 61.08 & 16.34 & $-.20 * * *$ & $-.32 * * *$ & $.82 * * *$ & 1 & & & & \\
\hline $\begin{array}{l}\text { 5. SCPAS } \\
\text { (models) }\end{array}$ & .96 & 55.25 & 18.06 & $-.17 * *$ & $-.37 * * *$ & $.67 * * *$ & $.78 * * *$ & 1 & & & \\
\hline 6. CFQ_F & .96 & 60.36 & 23.73 & .07 & $.23 * * *$ & $-.37 * * *$ & $-.35^{* * *}$ & $-.36 * * *$ & 1 & & \\
\hline 7. CFQ-BI & .97 & 36.35 & 21.37 & $.22 * * *$ & $.42 * * *$ & $-.45 * * *$ & $-.53 * * *$ & $-.53 * * *$ & $.69 * * *$ & 1 & \\
\hline 8. MAAS & .90 & 60.78 & 13.55 & .05 & $-.12 *$ & $.22 * * *$ & $.21 * * *$ & $.24 * * *$ & $-.36 * * *$ & $-.33 * * *$ & 1 \\
\hline 9. EDE-Q & .96 & 1.45 & 1.33 & $.39 * * *$ & $.59 * * *$ & $-.36 * * *$ & $-.48 * * *$ & $-.48 * * *$ & $.47 * * *$ & $.76 * * *$ & $-.23 * * *$ \\
\hline
\end{tabular}

Note. BMI = Body Mass Index; $\mathrm{BD}=$ Body Dissatisfaction (by the FRS); SCRS = Social Comparison Rating Scale; SCPAS = Social Comparison through Physical Appearance (with peers and models); CFQ_F = Cognitive Fusion Questionnaire (Fusion Dimension); CFQ_BI = Cognitive Fusion Questionnaire - Body Image; MAAS = Mindful Attention and Awareness Scale; EDE-Q = Eating Disorder Examination - Questionnaire (global score). $* p<.050 . * * p<.010$. *** $p<.001$. 


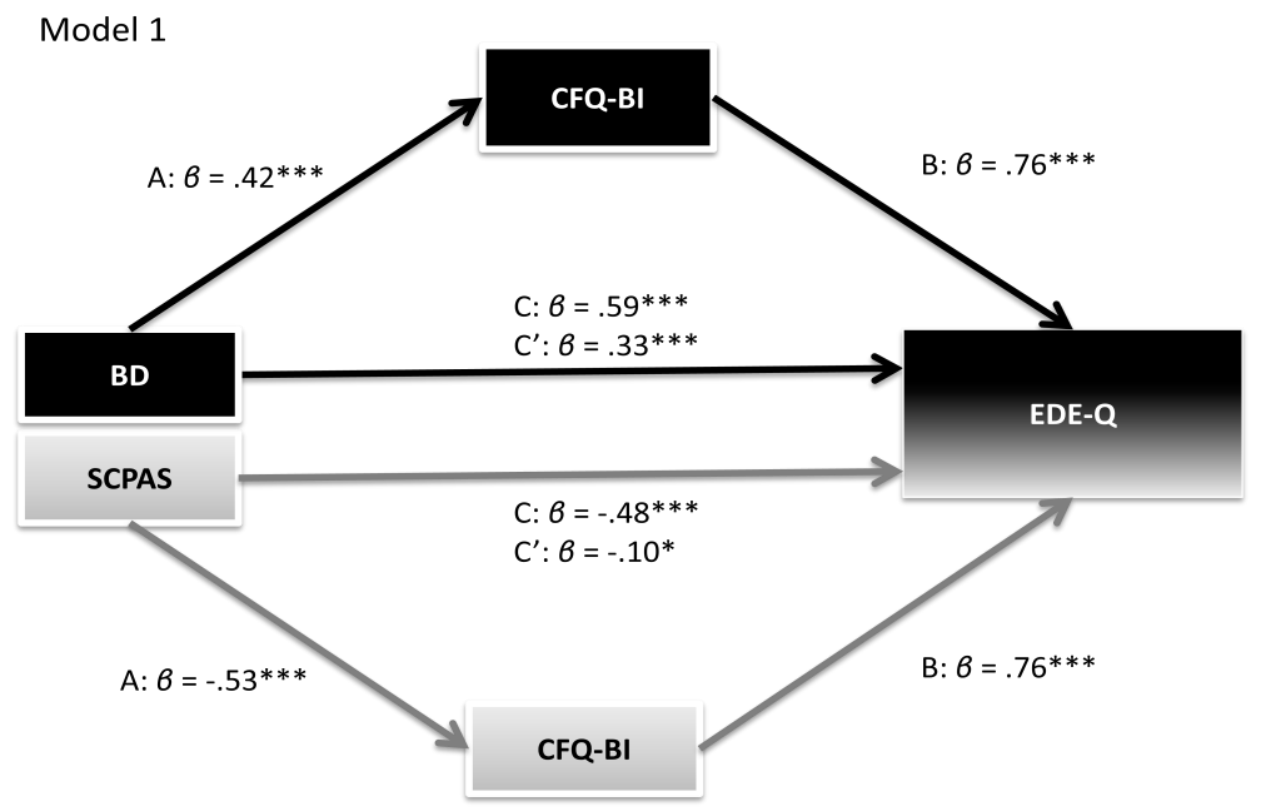

Model 2

Fig. 1. The mediator effect of body image-related cognitive fusion (CFQ-BI). $A=$ the relation between the independent variable and the mediator, $\mathrm{B}=$ the relation between the mediator and the dependent variable, $\mathrm{C}=$ the direct effect of the independent variable on the dependent variable, $C^{\prime}=$ the indirect effect of the independent variable on the dependent variable controlling for the mediator; $* \mathrm{p}<0.05, * * \mathrm{p}<.01, * * * \mathrm{p}<.001$. 